\title{
Study on the Strategy of Reading and Spreading of University Library in the Full Media Era*
}

\author{
Ying Zeng \\ Library \\ China West Normal University \\ Nanchong, China
}

\begin{abstract}
It has been discussed the characteristics of College Students' reading in the all media environment. It has been analyzed the problems existing in the new media reading promotion of Chinese university libraries, and has been put forward the reading promotion strategy of University Libraries under the all media environment, including: enhancing the librarian capacity and strengthening the integration of departments, stimulating the reading influence of the hot topics in the era, combining reading technology with enhancing reader experience, and combining diversified communication with group cooperation.
\end{abstract}

Keywords—the full media era; university library; reading promotion; strategy

\section{INTRODUCTION}

With the development of technology, the new media has been developed rapidly, and has become an extremely farreaching media ecological phenomenon, opening the era of all media. Reading as a traditional media and new media focus areas, is inevitably influenced by the media age, reading printed books to extend from analog video and digital audio broadcasting, multimedia reading, reading activities expand from a fixed location, fixed time to any time, any place, at the same time the reader's reading and thinking mode the value judgment standard, great changes have happened. Therefore, in the face of the drastic change in the media age, how to accurately grasp the characteristics of university students' reading in the era of media and how to effectively play the advantages of media convergence, so as to further promote the reading in Colleges and universities, is a topic worthy of careful study.

\section{COLLEGE STUdENTS' READING CHARACTERISTICS UNDER THE FULL MEDIA ENVIRONMENT}

The college library readers generally have a strong curiosity; accept new knowledge quickly, strong spending power characteristics. They soon become the first users of the new media. Once the new media conforms to their values and gets their approval, it will soon be accepted. The new media will have a strong stickiness to the readers of colleges and universities, and have a great impact on their study and

*Supported by the Meritocracy Research Funds of China West Normal University "Study on the reading promotion service of University Library in the full media era" (17YC413). life. Therefore, in the context of the emergence of new media and the continuous integration of media, new characteristics have emerged in university readers.

\section{A. Abnormally Sensitive to Emerging Digital Reading Media}

The rapid development of multimedia reading enriches the content form, the visual perception of the text written language is no longer the only choice of readers, readers as a resilient group quickly using a variety of new reading media, reading the digital gradually. On the one hand, due to the special emotional value of paper books for thousands of years, the traditional paper reading is still one of the main ways of reading for university readers, but its influence is decreasing rapidly. On the other hand, because of the emergence of new reading media, mobile portable terminal has become the mainstream reading medium, and multiscreen terminal is a common phenomenon. At present, the new digital reading methods such as micro reading, listening and reading are popular among the readers of the University. Micro reading and listening and reading, as a way of reading without needing to occupy the fixed time and arbitrary way, are in line with the characteristics of Current College Readers' fast pace of life and fragmentation. And smart phone, IPAD, notebook computer and other reading terminal collocation, for readers to adapt to different environment to provide conditions for reading. Your paper book is downloaded to the intelligent mobile phone, IPAD, computer and other playback devices, used to use class, either online or offline for rest, eating, and waiting time of micro reading, or paper books through audio conversion software made by ear, "reading", "knowledge will change communication mode of transmission" be assisted by way of reading readers' favorite.

\section{B. "Stereoscopic Reading" Is Widely Welcomed}

The paper books as the representative of the "plane reading" because of the form of a single, monotonous and often fail to attract the reader's interest, and with the features of high technology to "three-dimensional reading" emphasizes the full range of readers, feel the importance of the reader participation, which is widely welcomed by the readers of university. The "three-dimensional reading" Correa T, 2010). refers to the characteristics and reading habits of different readers, all aspects of resource integration in University, launched the digital and virtual books, lectures, 
exhibitions and other reading activities, the readers can get the knowledge of inspiration is no longer confined to the form of text, but also acquire knowledge inspiration from the sound, light and shadow, like, somatosensory and other forms of. At the same time, 3D technology, wearable devices, holographic projection technology and other latest technology in the "stereoscopic reading" activities have been widely promoted, and enable college readers to experience the pleasure brought by reading, thus being widely welcomed by readers.

\section{The Strong Demand for Individualized Reading}

Almost all university libraries are faced with such embarrassing reality that the amount of paper books and periodicals has been decreasing year by year. This is due to borrowing a thick, old and monotonous book in a large part of Young College Readers' concept, which is a waste of time. They love that is personalized, fast food style information, information display of the form to be out of the ordinary, such as in the language style and they are willing to accept the fashionable language, writing on the favor using the body of words, tend to reflect the plot pictures and video combination, the table of contents is vivid, visual effects on the love of beautiful interface etc. and they think it can reflect their taste in reading, to help them get information from their friends. Only with these elements of information, they think reading interesting, meaningful and memorable, it requires universities in the promotion of digital reading paper books will not simply digital, but to build an excellent editorial team to provide innovative content, pictures and video quality fine audiovisual works.

\section{The Process of Reading and Acquisition Emphasizes Interactivity}

The new media has redefined the reader to obtain information, create interactive mode of two or more persons, making, blogs, podcasts, micro-blog, WeChat, Wikipedia, renren.com, Youku potatoes video, and Youtube Facebook continue to lead to strong shock effect in the network world. The reader only recipients of information, they lack the expression of individuality, self-channel, and now they can through the Internet to the school and even the whole world to speak or publish content, any reader anywhere in the campus as long as they can by any means "net", can be achieved and the information service of the library staff, in the same opinion of readers, readers, and get instant feedback. They are happy to attract people to interact with them through this efficient way of expression, and enjoy a good sense of experience and their own value in the process of interaction (Ma,2013.).

\section{E. Keen to Make Use of Cross Media to Form a Reading Circle}

Under the background of diversified values and extensive media influence, weak voice can also respond quickly, and vulnerable groups can also attract wide attention. Some readers may seem aloof, be scanty of words in real life, little attention by others, but they are interested in WeChat, microblog, as the other cross media platform to express personal views. The content may be the content of the positive energy, or the content of the negative energy. However, due to the cross media technology can be real-time online, word, voice and image coexist; "in the loop" information update can immediately attract others' attention, always attracting likeminded people to participate in the discussion. So they will become the focus of the Internet. The discussion group can be evolved into all kinds of interesting "popular" network communities.

\section{Problems IN THE PRomotion OF NeW MediA READING IN UNIVERSITY LIBRARIES IN CHINA}

\section{A. Limited to the Traditional Reading Service Mode, the New Media Reading and Popularizing Methods Are Generally Missing}

Through the author's research found that although the University Library in the construction of literature information keep up with the pace of the times, the effort to build a digital library, the purchase of electronic resources is extremely rich, but in the reading service and promotion did not break the traditional mode, new media lack of reading promotion. In some colleges and universities that open mobile libraries, some university libraries have set up a striking and independent plate below the homepage. They can attract attention quickly, and click links to get help and instructions for mobile libraries. However, some libraries in universities and colleges set up mobile library or mobile library projects, which are hidden in the list of columns. There is not any prominence. This mobile reading service has not been promoted and publicized in the Internet media.

Carry out the e-book reading services and the promotion of colleges and universities are rarely, in contrast, basically every university library homepage can be found on the "Reading Festival", "reading", "library propaganda month" traditional reading promotion propaganda traces, these activities are almost invariably specific content followed the "reading essay" and "television show" and "bibliography" project, especially the "bibliography". Many university libraries have set up similar promotional activities, but not in time into the new media elements, but still use a simple list of bibliographic information, the original dull, unattractive, lack of pictures, the book cover scanning picture information, also the lack of reason to recommend, comments and other interactive information, but did not provide the collection ebook links. Only a small part of the library's "book review" column, in addition to publishing the recommended books, but also with "bean contents", and provides links to related resources of the book, such as watercress, Google, Baidu, e, superstar, Duxiu reading link, at the same time with the trend of reading books, books provide information storage mobile phone two-dimensional code to facilitate the readers will be retrieved in the portable mobile phone (Kane, 2009).

\section{B. Limited Ways to Promote New Media Reading}

Most of the ways that university libraries carry out the promotion of new media are basically limited to the homepage of our school library. A few university libraries have opened Tencent, Sina and Renren micro-blog to interact 
with readers. According to the author's visit statistics, the library micro-blog is not as attractive as the BBS of the library, and it is difficult to get rid of the cold situation. I visited some college students usually visited relatively high school in other departments ", for example, the Communist Youth League propaganda department, students, office of academic affairs, only the Zhejiang University of the school site to set up" reading - New Youth reading promotion program, the authorities have no other university related links. In a library in Beijing, Shanghai area survey shows that mobile reading service promotion, readers learned library provides mobile reading service channels are still mainly traditional, such as "library website", "Library bulletin", "library SMS notification", the preferred way to implement a mobile library reading promotion the corresponding also focus on "library website" and "library publicity column". In terms of new media reading promotion, university libraries have not yet broken through the Department's limitations, seeking joint promotion of relevant departments within schools, and expanding a wider promotion channel.

\section{New Media Reading Promotion Method}

In the University Library in the new media to carry out reading promotion and the specific content and no obvious differences are the basic books "recommended" and "comment", but will promote content "traditional electronic reading era", and further information fusion, enrich the recommended books, provides a selective the content is more intuitive and more useful to the readers. But on the whole, the promotion methods and recommendations and did not reflect the characteristics of the University, there is no obvious difference between promotion and commercial digital library, network operators, and is closely related to the lack of cultural and historical content, resulting in the university library is difficult to play their own unique attraction.

\section{THE READING PROMOTION STRATEGY OF UNIVERSITY LIBRARY UNDER THE FULL MEDIA ENVIRONMENG}

In recent years, colleges and universities have actively built smart campus, and achieved remarkable results in digitalization and information construction. This objectively provides a great convenience for university readers to carry out digital reading. In all media background, the promotion of reading media, means, channels, characteristics of readers have undergone tremendous changes, therefore, must conform to the characteristics of college media background in the promotion of reading promotion, integrating the various publicity media, according to the characteristics of high school readers, reading promotion strategy optimization.

\section{A. Improving the Ability of Librarians and Strengthening the Integration of the Department}

Three-dimensional propaganda reports required to transform the existing promotion process, to promote the depth of integration power of the campus, whether the library staff in what position, under the background of all media to promote reading all of its proposed "expert" work requirements, not only to have your life writing ability, can easily cope with short and long network news reports in writing, but also possess excellent photography, video, audio and video processing ability, but also master the full media marketing operation ability, to promote reading works more exchanges, communication. Strengthen the sector integration is mainly to strengthen and promote the school library is responsible for reading the Propaganda Department propaganda department in power integration of reading promotion, this is because the two departments collected content, propaganda and reporting form and focus with the draft demand difference, which can set up a joint editorial team background unified planning, integration, promotion and marketing.

\section{B. The Influence of Reading on the Hot Issues of the Times}

The library uses the new media to carry out the reading promotion. On the one hand, we should consider the psychological needs of the students, but they cannot be discriminated against the students' taste. According to the demand characteristics of College Students' mobile reading, some scholars put forward that library mobile reading content should mainly provide recreational and informative content, including weather forecast, entertainment information, news, transportation and map guides (Chen, 2012). The author thinks, provide entertainment information and library service is not long, and can provide the information of the commercial entertainment sites in the beyond count, the content, the library does not have any competitive. In the promotion of new media reading, the library should not only pay attention to the needs of the university students, but also pay attention to the cultural and educational benefits of the library. For example, contemporary college students are very concerned about social hot issues, and libraries can seize this requirement to launch relevant reading topics in a timely manner.

\section{The Combination of Reading Science and Technology and Enhancing the Sense of Readers' Experience}

The development of new media blurs the boundaries of the reading media and gradually combines with the wisdom library. It not only provides readers with diversified ways of reading, enlarges the breadth of reading, but also changes the form of knowledge organization, and increases the depth of reading, thus greatly expanding the connotation and denotation of Smart Library. A book, a cup of tea, a traditional way of reading in the afternoon is no longer a popular reading method for the readers of colleges and universities. The readers of colleges and universities, especially the young students, prefer to reflect the scientific, modern and humanized way of reading. The university library should introduce wisdom library concept, and constantly improve the level of science and Technology Museum, sound, light and shadow, visual, somatosensory, intelligent recognition technology is gradually applied to the reading promotion activities, the overall sense of let readers extend to multiple body organs from the eyes by the reader experience, zero distance, full azimuth, panoramic view, multi angle experience knowledge, experience of high-tech 
reading. Readers will no longer be a learner who can only read books, but also can be incarnated as experiencer, participant and creator of knowledge, enjoying the endless charm of intelligent reading (Wang, 2015).

\section{The Combination of Diversified Communication Methods and Group Cooperation}

Social networking sites have diversified characteristics in communication, specifically manifested in the diversification of media, the diversity of communication functions, the diversity of language expressions, and the diversification of cultural concepts(Zhao, 2011). By using the Internet, the use of text, audio and video and network symbols are non-face transfer information, exchange emotion communication activities, in order to achieve the combination of multimedia ways to express themselves to the viewer with a more powerful visual impact, so that the outside of a full understanding of the individual. In the integration of a variety of forms and techniques of traditional network information exchange, such as Blog, BBs, Email, IM and other forms of social networking sites were added at the same time, in order to meet various application needs of users, is a kind of traditional network advantages but also has its own characteristics of social system. The purpose of social networking sites is to gather like-minded peers through instant messaging channels such as Internet, and create more valuable cooperative information by colliding the collective power and different cultural concepts. Provide plenty of multimedia social networking site for user groups, individual advantage in the group in the play, group collaboration activities in social networking platform, to meet the small groups inside common groups also increased demand, belonging to individual self-group identity and sense of identity.

\section{CONCLUSION}

In short, for the promotion of reading media integration provides a new platform for the promotion of reading, science and technology, through the platform, the library can integrate various media advantage, improve the reading promotion effect, readers not only have the opportunity to see and hear ", but also" and "rights. However, when we look back the connotation and characteristics of media convergence of College Readers, in fact, is not difficult to find, which appears between the two kinds of different objects actually embodies the common pursuit of value, namely, autonomy, independence, cooperation, and this is where the value of reading promotion strategy to pursue. Therefore, under the all media environment, the university library takes the lead in the situation, implements the autonomy, independence and cooperation concept in the reading promotion activities, and optimizes the reading promotion strategy.

\section{REFERENCES}

[1] Correa T,Hinsley A W, de Zuniga H G ."Who interacts on the web? The intersection of users personality and social media
use,"Computers in Human Behavior, vol 26,PP.247-253, November 2010 .

[2] A.F.Ma."The interactive mode and practice of University Library and readers," Library work and research,vol.2,PP.94-96, February 2013.

[3] Kane G C, Fichman R G, GallaugherJ, Glaser J. "Community relations2.0,"Harvard Business Review ,vol.87,PP.45-50,May 2009.

[4] W.J.CHEN."The transformation of reading culture in the context of media integration,” International Press,vol.4,PP.90-94,April 2012.

[5] Y.M.WANG. "Cross media reading: the new trend of integration of 2020 and MOOCs,"China Educational Technology,vol.1,PP.22-28, January 2015.

[6] Y. Zhao."The communication characteristics and influence of SNS website," Media,vol 9,PP.57-58, September 2011. 